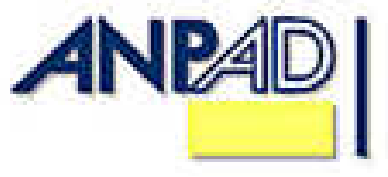

Disponível em

http://www.anpad.org.br/rac

RAC, Curitiba, v. 15 , n. 5, art. 6 ,

pp. 897-917, Set./Out. 2011

$(c)$ EY-NG

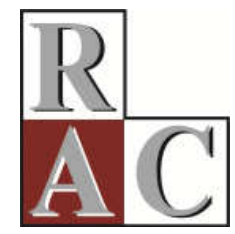

\title{
Trabalho Imaterial Bancário, Lazer e a Vivência de Dilemas Pessoais Contemporâneos
}

\section{Immaterial Bank Work, Leisure and the Experience of Personal Contemporary Quandaries}

Letícia Weber *

E-mail: leticia_weber@yahoo.com.br Universidade Federal do Rio Grande do Sul - UFRGS

Porto Alegre, RS, Brasil.

Carmem Ligia Iochins Grisci

E-mail: cligrisci@ea.ufrgs.br

Universidade Federal do Rio Grande do Sul - UFRGS

Porto Alegre, RS, Brasil.

Copyright (C) 2011 RAC. Todos os direitos, até mesmo de tradução, são reservados. É permitido citar parte de artigos sem autorização prévia, desde que seja identificada a fonte. 


\title{
Resumo
}

Este artigo busca compreender a interação do trabalho imaterial com o lazer nos modos de trabalhar e de viver de bancários inseridos em um Banco Múltiplo Privado; pondera-se também se tal interação se configura em dilemas pessoais contemporâneos. O estudo, de caráter exploratório, contou com a participação de 15 sujeitos que foram entrevistados em seus locais de trabalho. A análise de conteúdo se deu à luz do referencial teórico sobre trabalho imaterial bancário, lazer e dilemas pessoais contemporâneos, tendo como suporte autores como Bauman (2007), Castells (2000), Dumazedier (2008), Dejours (2008) e Gaulejac (2007). Os resultados indicam que o trabalho imaterial bancário interfere no lazer dos bancários; pode até mesmo impedi-lo, desencadeando vivências de dilemas pessoais, uma vez que constantemente suas escolhas relativas ao dever e ao lazer não encontram alternativas satisfatórias. Se optam pelo lazer, preservam as relações familiares, mas sofrem o desprezo dos colegas; se optam pelo trabalho, preservam as relações de coleguismo, mas sofrem as reclamações da família, por exemplo.

Palavras-chave: trabalho imaterial; trabalho bancário; lazer; dilemas pessoais.

\begin{abstract}
This article seeks to understand the interaction between immaterial work and leisure in the ways that workers from a private commercial bank live and work, and whether this interaction could be considered as personal contemporary quandaries. The study, which is of an exploratory nature, involved 15 individuals who were interviewed at their work stations. The content analysis gave birth to the theoretical framework on immaterial banking work, leisure and personal contemporary quandaries, being supported by authors such as Bauman (2007), Castells (2000), Dumazedier (2008), Dejours (2008) and Gaulejac (2007). The results show that immaterial banking work interferes with and even impedes leisure for bank workers and can result in personal quandaries, since their choices concerning duty and leisure do not result in satisfactory alternatives. If they opt for leisure, they preserve their family relationships but are scorned by their colleagues; if they choose work, they preserve their relationships with their colleagues but receive complaints from their families, for example.
\end{abstract}

Key words: immaterial work; bank work; leisure; personal quandaries. 


\section{Introdução}

A velocidade assumiu a tônica dos dias atuais, ao reger mudanças constantes, e afetar os modos de trabalhar e de viver dos sujeitos contemporâneos. Entre os autores que tratam da questão da velocidade, associando-a a evoluções tecnológicas, encontram-se Virilio (1996), Castells (2000) e Gaulejac (2007). Para Virilio (1996) a velocidade é potenciada pelo desenvolvimento da tecnologia. Para Castells (2000) a reestruturação do capital acontece na direção de uma maior flexibilidade, da presença massiva das tecnologias de informação e comunicação (TICs) e também de um controle cada vez maior da força de trabalho. Para Gaulejac (2007) as evoluções tecnológicas foram anunciadas como libertadoras do sujeito, embora, de fato, o coloquem sob pressão, pressão do sempre mais, da concorrência que se estabelece entre os sujeitos, das férias cada vez mais curtas, passíveis de ilustração por meio da expressão não tenho mais tempo para mim.

Fala-se muito dos ingredientes para a felicidade, tais como a família, a amizade, a autonomia, a autoestima, as horas de lazer e o tempo livre. Com os novos modos de trabalhar e experimentar o tempo da perspectiva da velocidade, estariam estes ingredientes sofrendo algum abalo? Se, sob a noção de trabalho imaterial, compreendido como aquele trabalho que requer disponibilidade total do sujeito para sua realização (Gorz, 2005; Grisci, 2006; Lazzarato \& Negri, 2001), é possível afirmar a indissociação entre trabalho e vida, como se apresentaria para os trabalhadores bancários, em especial, a questão do lazer? Teria o lazer algo a dizer dos dilemas pessoais contemporâneos?

Os bancários configuram uma categoria de trabalhadores cujos modos de trabalhar e de ser refletem muitas das transformações do trabalho contemporâneo e associam-se plenamente à noção de trabalho imaterial devido a suas atuais formas de estruturar e organizar o trabalho, em especial, via o abandono de rígidos padrões espaciotemporais, a utilização de sutis modos de controle, e a adoção de novas tecnologias da informação e comunicação (Grisci, 2008). Desta forma, toma-se a categoria numa posição de destaque em face das questões associadas ao lazer. Por lazer entende-se, conforme apresenta Dumazedier (2008), o conjunto de ocupações às quais o sujeito pode entregar-se de livre e espontânea vontade, seja para repousar, divertir-se e entreter-se. Uma vez que, por dilema, se entende a vivência de uma situação cujas alternativas de resolução se apresentam insatisfatórias, atingindo todos os campos da vida individual na sociedade líquido-moderna, como ressalta Bauman (2007), estaria o lazer associado aos dilemas pessoais contemporâneos? Perante situações embaraçosas da vida líquida, encontrar-se-iam os bancários, por exemplo, entre o dever e o lazer? Que estratégias de enfrentamento engendrariam quanto a dilemas relativos ao trabalho e ao lazer, caso assim se configurassem? Diante das questões norteadoras expostas, elegeu-se a seguinte questão de pesquisa: como a atual configuração do trabalho, sob a noção de trabalho imaterial, interfere no lazer de bancários de um banco múltiplo privado? Pode tal interferência constituir-se em dilemas pessoais?

Buscando responder a tal questão, propôs-se como objetivo geral compreender a interação do trabalho imaterial com o lazer nos modos de trabalhar e viver de bancários inseridos em um Banco Múltiplo Privado, ponderando-se se tal interação se configura em dilemas pessoais contemporâneos. Os objetivos específicos destinaram-se a caracterizar os modos de trabalhar de trabalhadores bancários de um Banco Múltiplo Privado; descrever as formas de lazer dos bancários deste banco; verificar se e como os modos de trabalhar interferem no lazer destes bancários; e verificar se e como a interação dos modos de trabalhar com o lazer se constitui em dilemas pessoais para estes bancários.

\section{Modos de Trabalhar e de Viver e os Dilemas Pessoais Contemporâneos}

As transformações aceleradas que caracterizam o mundo contemporâneo, facilitadas pela evolução tecnológica, acarretaram novos modos de trabalhar e de viver que, por sua vez, se refletem no lazer e podem intensificar a vivência de dilemas pessoais, como se verá nos itens apresentados a 
seguir. A relação que se estabelece entre trabalho imaterial, lazer e dilemas, se mostra pertinente, até mesmo, por sua carência na produção científica atual.

\section{Trabalho imaterial bancário}

Castells (2000) destaca que espaço e tempo são as principais dimensões da vida humana. Estes estão sendo modificados, transformando a sociedade em sociedade em rede. Nas sociedades contemporâneas, o fluxo de informação é intenso, há um apelo constante à velocidade, à rapidez, à passagem, ao movimento. Enriquez (1995) destaca que as consequências desta velocidade exigida são temíveis, mesmo que elas não apareçam imediatamente.

Bauman (2007) argumenta que é preciso toda a velocidade de que se é capaz para ficar no mesmo lugar. O autor ressalta que a vida líquida é uma vida precária, vivida em condições de incerteza constante. Além disso, vive-se em constante autoexame, autocrítica e autocensura, alimentando a insatisfação do eu consigo mesmo. Para Virilio (1996, p. 130) "quanto mais cresce a rapidez, mais decresce a liberdade".

Essa nova experimentação do tempo encontra-se amplamente relacionada com a noção de trabalho imaterial, uma vez que os novos modos de trabalhar são potenciados, segundo Grisci (2006), pelas novas tecnologias da informação e comunicação e a instalação de sutis modos de controle. A autora explica que trabalho imaterial é "o conjunto de atividades corporais, intelectuais, criativas, afetivas e comunicativas inerentes ao trabalhador, atualmente valorizadas e demandadas como uma imposição normatizadora de que o trabalhador se torne sujeito ativo do trabalho como condição indispensável à produção" (Grisci, 2006, p. 327).

Pelbart (2000) ressalta que o trabalho imaterial é trabalho afetivo, no sentido de que seus produtos são intangíveis: um sentimento de tranquilidade, bem-estar, satisfação, excitação, paixão - ou até mesmo a sensação de estar simplesmente conectado ou de pertencer a uma comunidade. Assim, as demandas que caracterizam o trabalho imaterial tomam pensamento, potência, sensibilidade, sociabilidade e afetividade dos sujeitos numa dimensão que implica a vida.

Mansano (2009) destaca a importância de investigar quais as exigências subjetivas desses novos modos de trabalhar na vida dos sujeitos, no que se refere ao seu local de trabalho e para além dele, pois a noção de trabalho imaterial envolve a complexidade de um sujeito transformado pela aquisição de conhecimento e interação com o meio social, reforça a autora.

Gorz (2005) lembra que todo o trabalho, seja na produção industrial seja no setor de serviços, contém um componente de saber, cuja importância é crescente. O trabalho de produção material, mensurável, é agora substituído pelo trabalho imaterial, ao qual padrões clássicos de medida não mais podem aplicar-se. O trabalho imaterial é "impossível de quantificar, estocar, homologar, formalizar e até mesmo de objetivar" (Gorz, 2005, p. 17). O que importa é a inteligência, a imaginação, o saber dos sujeitos. O que conta são as qualidades de comportamento, qualidades expressivas e imaginativas e o envolvimento pessoal na tarefa, complementa o autor.

Segundo Lazzarato e Negri (2001), o trabalho imaterial é tido, ainda, como aquele tipo de trabalho que se extingue no momento de sua produção, que é agregado pelas características pessoais e intrínsecas do próprio trabalhador. Dizem os autores:

quando o trabalho se transforma em trabalho imaterial e é reconhecido como base fundamental da produção, este processo não investe somente a produção, mas a forma inteira do ciclo reprodução-consumo: o trabalho imaterial não se reproduz (e não reproduz a sociedade) na forma de exploração, mas na forma de reprodução da subjetividade (Lazzarato \& Negri, 2001, p. 30).

A subjetividade é coletiva, histórica e social, no entanto, é vivida pelos sujeitos, podendo estes responder ou consumir a subjetividade produzida de diferentes formas, balançando entre dois polos, 
conforme apresentam Guattari e Rolnik (1996). O primeiro polo expressa uma relação de alienação e de opressão, e corresponde ao processo denominado pelos autores de individualização, que consiste em bloquear o processo de resistência e criação, afirmando a submissão e instaurando padrões universais, massificadores e individualizantes vigentes e, muitas vezes, assumindo a culpa para si. O segundo, expressa uma relação de expressão e de criação, processo chamado pelos autores de singularização, onde o sujeito reapropria-se dos componentes da subjetividade, como um ato de resistência, associando-se e afirmando outros modos de ser, outras sensibilidades, outras percepções.

É interessante observar, conforme destaca Grisci (2008), que os novos modos de gestão contribuíram para moldar outras formas de trabalhar e viver dos trabalhadores bancários. A estes sujeitos passou a ser solicitar-se maior flexibilidade, adaptabilidade, participação e requalificação constante, autonomia para pequenas decisões e afetividade nos relacionamentos. Mas também excesso de exposição ou falta de privacidade e disponibilidade total na forma de engajamento subjetivo diante das demandas sempre mutáveis. Esse cenário de controle emocional, destaca a autora, gera adesão voluntária aos modos de gestão por meio da gestão de si compreendida como autocontrole; e este controle não se limita aos modos de trabalhar; atinge igualmente os modos de viver dos sujeitos e das coletividades.

\section{Lazer}

Para Dumazedier (2008) lazer é o conjunto de ocupações às quais o sujeito pode entregar-se de livre e espontânea vontade, seja para repousar, divertir-se, recrear-se e entreter-se; ou ainda para desenvolver sua formação desinteressada, sua participação social voluntária, ou sua livre capacidade criadora, após cumprir obrigações profissionais, familiares e sociais. Segundo o autor, lazer é uma escolha individual, ajuda o sujeito a sair da rotina, é benéfico para a saúde e é buscado pelo prazer e satisfação que proporciona.

Marcellino (2006) lembra que o termo lazer é carregado de preconceitos, motivado por pretenso caráter supérfluo dessas atividades, contrapondo-se à situação socioeconômica, e pela sua utilização como instrumento ideológico, contribuindo para o mascaramento das condições de dominação nas relações de classe. $\mathrm{O}$ descanso e o divertimento são os valores comumente mais associados ao lazer. $\mathrm{O}$ autor reforça que o importante nessas oportunidades é o repouso, a higiene mental, a quebra da rotina e a liberação da imaginação.

Evans e Bartolomé (1980) pontuam, de acordo com sua pesquisa, que o lazer normalmente está associado a quatro perspectivas diferentes, todas, porém, ligadas à vida profissional: lazer como recuperação (descansar); lazer como relaxamento (aliviar as tensões); lazer como investimento/dedicação à vida privada (passear com os filhos) e lazer como desenvolvimento pessoal (segunda carreira). O lazer, dentro desta perspectiva, passa a ser mais um concorrente na distribuição do tempo de não-trabalho.

Brett e Stroh (2003) lembram que normalmente os méritos familiares não fazem ocupar revistas ou sair na mídia, mas, sim, o papel profissional. Diferentemente do papel no trabalho, o papel na família proporciona menos oportunidades de realizar uma contribuição percebida pela sociedade, de ter reconhecimento imediato e feedback positivo, já que a compensação amorosa e afetiva pode não ser tão imediata, além de geralmente não ter este caráter tão público, reforçam os autores.

Para Perista, Maximiano e Freitas (2000) o tempo de não-trabalho compreende todos os tempos utilizados em atividades que não visem à remuneração ou com ela não tenham vínculo, tais como os tempos utilizados com a família, com o cônjuge, com atividades sociais, com lazer e com amigos, entre outros. Os autores reforçam que, no caso do tempo, a percepção pode variar, pois esta noção de tempo é relativa e influenciada pelo desenvolvimento do conceito de tempo como construção social.

Cada sujeito administra seus tempos de trabalho e de não-trabalho de acordo com variáveis socioeconômicas e culturais, sobre as quais ele tem mais ou menos governabilidade, o que influencia sua percepção do significado do tempo, que tem, neste sentido, uma dimensão mais subjetiva, 
passando a ser de construção social. Assim, cada sujeito também vai definir o que é lazer para si e quanto tempo quer ou pode dedicar a estas atividades. O que é lazer para um, pode não ser para outro.

Segundo Dumazedier (2008) é difícil classificar as atividades ligadas ao lazer, pois esta questão é bem pessoal, além de estar muito ligada à classe social. Mesmo assim, o autor propõe cinco categorias, de acordo com o interesse predominante que as envolve, estabelecidas conforme as necessidades de realização do corpo e do espírito dos indivíduos:

1. Lazeres físicos: atividades esportivas, caminhadas, sair para dançar, viagens e passeios, o foco não são os exercícios físicos, mas as atividades práticas que elevem a sensação de bem-estar.

2. Lazeres artísticos: teatro, concerto, cinema, museu, espetáculo esportivo, que se referem aos realizados fora de casa.

3. Lazeres práticos: trabalhos manuais, jardinagem, culinária, ligados às práticas cotidianas, realizados em casa.

4. Lazeres intelectuais: leituras não ligadas aos interesses profissionais.

5. Lazeres sociais: recepções, visitas feitas ou recebidas, sair com amigos e festas familiares.

Bacha, Vianna, Souza e Perez (2008) concluíram que há diferenças significativas nas escolhas em relação às atividades de lazer entre as diversas faixas etárias e dentro delas, influenciadas pela renda média familiar mensal e gasto médio com lazer. Algumas atividades, segundo os autores, são apreciadas em todos os segmentos etários, como é o caso de passear /frequentar shopping, viajar, ler revistas e assistir à programação da $\mathrm{TV}$, destacam os autores.

França (2009) lembra que, entre os executivos, é comum que sua carga horária ultrapasse 50 horas semanais. Esta situação se estende nos finais de semana, já que muitos executivos não conseguem desligar-se da organização, e não raro dedicam parte do final de semana na resposta a emails, leitura de documentos da empresa ou pensando no que irão fazer na próxima semana. A dedicação excessiva ao trabalho pode limitar o desenvolvimento de outras atividades e interesses, como o lazer, atividades culturais e educacionais, hobbies ou o relacionamento familiar. Nas horas vagas, muitos tentam praticar um hobby, caminhar, jogar futebol, ler ou ir ao cinema, namorar ou se relacionar com a família. Contudo nem sempre é possível conciliar o tempo livre, entre tantas outras obrigações. A autora salienta que o lazer é uma das compensações do trabalho; mas, apesar disso, ele é pouco praticado durante a vida do trabalho e, talvez, seja utópico imaginar que, na aposentadoria, esses trabalhadores possam substituir, facilmente, a vida de trabalho por uma vida de lazer.

Perista et al. (2000) falam do impacto das novas tecnologias no uso do tempo. Segundo os autores estas tecnologias sequestram o tempo da vida pessoal, tornando mais difuso o limite entre o que é trabalho e o que não é. O uso constante dessas inovações ligadas às telecomunicações, à microeletrônica e à informática, não resulta em redução da jornada de trabalho e não libera mais tempo de trabalho para a vida pessoal. Pelo contrário, acabam por propiciar a invasão pelo tempo de trabalho em outros espaços da vida dos trabalhadores, como o do lazer. Assim, há muito menos limite entre o espaço pessoal, de trabalho e social, ou seja, todo o espaço passa a ser espaços também de trabalho, reforçam os autores.

Tanure, Carvalho e Andrade (2007) também falam da invasão do trabalho nos espaços da vida privada, como o lar e o lazer, propiciados pelo uso cada vez maior de computadores portáteis, correio eletrônico e telefones celulares. A falta de tempo para o lazer é a principal queixa dos executivos estudados pelos autores. Gaulejac (2007) lembra que, por influência do gerencialismo, cada sujeito deve tornar-se o gestionário de sua vida, se fixar objetivos, avaliar seus desempenhos, tornar seu tempo rentável. "Na nova ordem mundial, dominada pelos valores de empreendimento, tudo é business" (Gaulejac, 2007, p. 179). Assim, os sujeitos não sabem ao certo quando trabalham ou quando não trabalham, como se estivessem sempre fazendo negócios. Pragmatismo, utilitarismo, competição, rentabilidade, entre outras premissas do gerencialismo, invadem os espaços privados. 
Lopez-Ruiz (2007) complementa, lembrando que a atenção do investimento e o gerenciamento de sua carreira e vida-empresa torna-se a meta principal a ser atingida por cada sujeito, segundo a lógica do sistema, o único motivo em sua vida, sua fonte de sentido.

\title{
Dilemas pessoais contemporâneos
}

\author{
Para Bauman (2007, p. 142):
}

se as novas circunstâncias exigem movimento rápido e um recomeço a partir do zero, os compromissos de longo prazo e quaisquer laços difíceis de desatar podem revelar-se um fardo incômodo - um peso a ser jogado ao mar. Não há, então, uma boa escolha. Não se pode ficar com a torta e comê-la - mas é exatamente isso que você é pressionado a fazer pelo ambiente em que tenta compor sua vida. Qualquer escolha que você faça, está arranjando confusão.

Esse é o aspecto central do dilema: uma situação vivida pelo sujeito como de difícil solução ou cujas alternativas se mostram insatisfatórias. No ambiente de trabalho, Gaulejac (2007, p. 25) lembra que o gestor: "deve ser humano quando é preciso, mas deve igualmente saber assumir suas responsabilidades diante de escolhas difíceis". Nesse sentido, destaca o autor, cada indivíduo pode ser ao mesmo tempo produtor e produto do sistema, ser o ator e o agente dele, fazê-lo funcionar, tanto quanto apoiá-lo.

De Vries (2004), ao analisar a vida de sujeitos em posição de liderança, mostra que, muitas vezes, eles tendem a confundir seu papel com sua identidade, e uma ruptura pode causar-lhes grande infelicidade, quando se tornam prisioneiros do seu papel. Estes sujeitos podem sentir como se o trabalho fosse a parte mais divertida da vida, que possibilita a maior carga de adrenalina e de prazer, vivenciando o fascínio que o cargo, o status, o poder e o dinheiro trazem para sua vida. A vida pessoal, afetiva e familiar normalmente se torna uma obrigação. $O$ papel profissional pode funcionar muito bem, pois eles se realizam; mas o grande dilema é gerenciar o limite entre trabalho, lazer, vida afetiva e família, conforme enfatiza o autor.

Segundo Edwards e Rothbard (2000), o desequilíbrio no desempenhar este papel pode dar-se pela compensação: a insatisfação ou os eventos negativos em uma das dimensões da vida predispõe a aumentar o envolvimento ou buscar recompensa em outra. Existem estratégias de busca de recompensa ou de compensação; e mais tempo dedicado ao trabalho pode ocasionar aumento no desempenho profissional, o que faz com que esta dimensão seja ainda mais valorizada, argumentam os autores.

Freitas (1998) observa que quem quiser sobreviver no mundo atual do trabalho está condenado a vencer e a apresentar resultados de produtividade recordes cada dia, potenciando, cada vez mais, a sensação de estar sempre devendo.

Para Tonelli e Alcadipani (2003), os sujeitos, nos dias que correm, têm tarefas, como a organização, o controle e a promoção da cooperação, que podem ser fragmentadas, intensas e, ao mesmo tempo, superficiais. Neste sentido, também pela própria característica do seu trabalho, está sempre presente uma sensação de que existem tarefas inacabadas, por fazer, o que colabora ainda mais para a sensação de dívida permanente.

Segundo Lopez-Ruiz (2007), um conjunto de valores e normas é atualmente promovido dentro das grandes corporações, orientando a conduta dos sujeitos que nelas trabalham. Dessa forma, são definidas e promovidas noções como empreendedorismo e capital humano, junto com outras como inovação, criatividade, flexibilidade, imbuídas de conotação e valoração social que ultrapassam, contudo, o âmbito corporativo e contribuem para delinear os traços de uma mentalidade econômica e a vincular as pessoas a um complexo de deveres. Para Gaulejac (2007) trata-se, na maior parte do tempo, de uma obrigação interiorizada. É devido a isso que ela é tão imperiosa. Segundo o autor, o sistema gerencialista que permeia a estrutura mental suscita um modelo de personalidade narcísico, agressivo, pragmático, sem estados de alma, centrado na ação e não tanto na reflexão, pronto a tudo 
para ter sucesso. Gera no sujeito tensão e agitação permanente que lhe fazem perder o próprio sentido da vida.

Há ainda a questão da saúde dos que sofrem os efeitos do aumento das tarefas e responsabilidades e do alto ritmo em que estas têm de ser realizadas, lembram Huy e Mintzberg (2003). Estas novas exigências que se lhes impõem incrementam a impressão de estar sempre em débito, uma tensão que traz o constante sentimento de dívida para com a empresa, reforçam os autores.

A hipersolicitação desafia a própria biologia, pois não admite as deficiências e as imperfeições, não tolera a diversidade. A diversidade tolerada é diversidade padronizada, que é expressa pelo modelo-padrão de beleza. Sant'Anna (2001) destaca que os conselhos de beleza acompanham esta lógica, principalmente voltados para as mulheres, atualmente muito difundidos. Para a autora o corpo passa a ser considerado a principal marca identitária, pensar o corpo deixou de ser uma heresia para significar um modo de fazê-lo render mais.

Evitar que o corpo seja um obstáculo para poder entrar em todos os lugares, passar por todos os tempos, navegar em meio a diferentes culturas. Por isso, o homem voltado à transparência também é inquieto e incerto, amedrontado de não ser suficientemente ágil, criativo, flexível. Buscando desvencilhar-se do peso de tudo o que tende a repousar sobre si, ele teme carregar muito corpo, muita memória, muita identidade (Sant'Anna, 2001, p. 25).

Sennett (2001), ao falar dos temores da vida moderna, ressalta que as medidas necessárias e os modos de viver para sobreviver na economia moderna podem colocar a vida emocional do sujeito à deriva. É a dimensão do tempo no novo capitalismo que mais diretamente afeta a vida emocional dos sujeitos fora do local de trabalho. A noção de não há longo prazo, transposta para a área familiar significa mudar, não se comprometer e não se sacrificar. O conflito entre família e trabalho impõe algumas questões sobre a própria experiência adulta, argumenta o autor. $\mathrm{O}$ capitalismo de curto prazo corrói o caráter dos sujeitos, sobretudo aquelas qualidades de caráter que ligam os seres humanos uns aos outros, e dão a cada um deles um senso de identidade sustentável. "As qualidades do bom trabalho não são as mesmas do bom caráter" (Sennett, 2001, p. 21).

Dejours (2008) fala da hiperatividade dos executivos, devido ao desempenho exigido em determinadas situações, levando-os a adotarem estratégias que os tornam susceptíveis ao aumento do uso de psicotrópicos e ao vazio, quando não conseguem seguir o ritmo imposto. Estas estratégias não se detêm no ambiente de trabalho e invadem a vida privada. O sujeito que está engajado em estratégias defensivas para lutar contra o sofrimento no trabalho não abandona seu funcionamento psíquico ao sair do trabalho. Para o autor não se pode conceber uma organização do trabalho sem sofrimento, mas organizações do trabalho mais favoráveis à negociação da superação desse sofrimento. O trabalho é central na dinâmica da vida, sendo fundamental na definição da identidade de cada sujeito.

\section{Procedimentos Metodológicos}

Por se tratar de um estudo de caráter exploratório, a presente pesquisa almejou obter a visão geral dos sujeitos a respeito do tema proposto. "Pesquisas exploratórias são desenvolvidas com o objetivo de proporcionar visão geral, de tipo aproximativo, acerca de determinado fato. Esse tipo de pesquisa é realizado especialmente quando o tema escolhido é pouco explorado" (Gil, 2007, p. 43). A pesquisa qualitativa e seus métodos de coleta e análise de dados são apropriados para um estudo exploratório, argumenta Roesch (2005). Embora o trabalho bancário seja tema vastamente pesquisado, a produção referente ao lazer e à vivência de dilemas pessoais a ele associado se mostra escassa.

Os sujeitos da pesquisa são trabalhadores bancários de um Banco Múltiplo Privado, assim classificado segundo o Banco Central do Brasil (BACEN, 2009). Trata-se de um banco comercial de abrangência internacional, posicionado entre os maiores bancos do Brasil e em atividade no país há cerca de 40 anos, durante os quais realizou aquisições de bancos regionais e nacionais. Os quinze 
sujeitos trabalham em duas agências deste banco, sendo uma a agência central, e outra uma agência que pertencia a um banco privado adquirido recentemente pelo Banco Múltiplo Privado.

As atividades destes sujeitos incluem principalmente atendimento a clientes; fechamento de negócios, como abertura de contas e cartão de crédito, venda de seguros, capitalização e planos de previdência; aplicação de recursos financeiros em fundos de investimento; e mais a concessão de empréstimos e financiamentos. A diferença está nas atividades dos gerentes gerais que contam com atividades administrativas da agência, incluindo, por exemplo, gestão de pessoal e controle de desempenho dos empregados e da agência. A Tabela 1 apresenta o perfil dos sujeitos deste banco.

Tabela 1

Sujeitos Banco Múltiplo Privado

\begin{tabular}{cccccccc}
\hline Entrevistado & Sexo & Idade & $\begin{array}{c}\text { Estado } \\
\text { Civil }\end{array}$ & $\begin{array}{c}\mathbf{N}^{\mathbf{0}} \text { de } \\
\text { filhos }\end{array}$ & Escolaridade & Cargo & $\begin{array}{c}\text { Tempo de } \\
\text { empresa }\end{array}$ \\
\hline E1 & M & 31 & Solteiro & 0 & Superior Completo & Gerente de Negócios & $10 \mathrm{a}$ \\
E2 & M & 33 & Casado & 0 & Superior Completo & Gerente de Negócios & 9 a \\
E3 & F & 25 & Solteiro & 0 & Superior Completo & Assistente Comercial & 3 a \\
E4 & F & 42 & Casado & 1 & Superior Completo & Gerente Geral & 20 a \\
E5 & F & 28 & Casado & 1 & Pós-graduação & Gerente de Negócios & 6 a \\
E6 & F & 41 & Casado & 2 & Superior incompleto & Gerente de Negócios & 22 a \\
E7 & F & 28 & Casado & 1 & Superior incompleto & Gerente de Negócios & 4 a \\
E8 & F & 39 & Solteiro & 0 & Pós-graduação & Gerente Geral & 21 a \\
E9 & F & 26 & Casado & 0 & Superior incompleto & Gerente de Negócios & $5 \mathrm{a}$ \\
E10 & F & 40 & Divorciado & 0 & Superior completo & Gerente de Negócios & 9 a \\
E11 & M & 25 & Solteiro & 0 & Superior completo & Assistente Comercial & $4 \mathrm{~m}$ \\
E12 & F & 20 & Solteiro & 0 & Superior incompleto & Assistente de Atendimento & 2 a \\
E13 & M & 21 & Solteiro & 0 & Superior incompleto & Assistente de Atendimento & 1 a \\
E14 & M & 21 & Solteiro & 0 & Superior incompleto & Gerente de Negócios & 2 a \\
E15 & F & 27 & Solteiro & 0 & Superior completo & Gerente de Negócios & $3 \mathrm{a}$ \\
\hline
\end{tabular}

Os dados foram coletados por meio de entrevistas semiestruturadas, realizadas nos meses de junho e julho de 2009, em locais de trabalho dos entrevistados, por meio de um roteiro de entrevista e tiveram duração média de 40 minutos. Elas foram gravadas com a autorização dos entrevistados e, posteriormente, transcritas.

O roteiro de entrevista contava com 25 questões: oito abordando aspectos dos modos de trabalhar; oito relacionadas ao lazer; e nove relativas à vivência de dilemas pessoais entre trabalho e lazer. Como é o seu dia a dia em função do seu trabalho? Que é lazer para você? Se houvesse uma situação de lazer programada e ocorresse uma solicitação de última hora no seu trabalho que fosse impeditiva, como agiria frente disso? São questões que exemplificam, respectivamente, os aspectos abordados.

O Sindicato dos Bancários da cidade foi contatado, para que o acesso às agências fosse facilitado. Das conversas com representantes sindicais surgiram dados secundários ilustrativos para a presente pesquisa. 
Para a análise dos dados, realizaram-se sequencialmente as três etapas básicas da análise de conteúdo, conforme orientação de Bardin (2004): a pré-análise, que é a organização do material; a descrição analítica, que é o estudo aprofundado e orientado, em princípio, pelas hipóteses e referenciais teóricos; e a interpretação inferencial, onde a reflexão e a intuição alcançam maior intensidade, embasados nos materiais empíricos, que estabelecem.

\section{Trabalho e Lazer no Banco Múltiplo Privado}

A apresentação e análise dos resultados privilegiam os aspectos relativos aos modos de trabalhar dos trabalhadores bancários, às suas formas de lazer e à interação dos modos de trabalhar com o lazer. As falas dos sujeitos permitem inferir a dinâmica do trabalho e da vida pessoal em constante interação, evidenciando que sua conciliação é preocupação constante, nem sempre com desdobramentos satisfatórios, em especial porque envolvem família, saúde e desenvolvimento profissional, três eixos aos quais seus medos e ansiedades estão associados.

Todos os sujeitos afirmam que os modos de trabalhar interferem nas atividades de lazer. Seus depoimentos apresentam aspectos em que o trabalho pode atrapalhar, ou até mesmo impedir estas atividades. Neste caso, os sujeitos demonstraram dificuldades em lidar com estas situações, evidenciando a vivência de dilemas.

\section{Modos de trabalhar}

"Eu faço de tudo" é a expressão que ilustra os atuais modos de trabalhar no Banco Múltiplo Privado. A ela associam-se a pressão e a cobrança por metas de vendas. Conjugar o verbo vender tornou-se, para os bancários, um imperativo.

"Eu faço de tudo, atendo o cliente, abro conta, ofereço empréstimo, produtos do banco, basicamente atendimento; eu escuto muita reclamação, respondo pelo gerente também. É bastante corrido, todo dia atendo muito cliente, costumo abrir o caixa também se precisa; costumo ouvir: "é o funcionário Bom Bril, 1001 utilidades!'” (E3).

Os relatos dos sujeitos a respeito de seu cotidiano de trabalho, conforme exemplifica o depoimento acima, permitem visualizar um trabalhador que em nada lembra os modelos tradicionais do trabalho bancário. Os novos modos de trabalhar mostram-se condizentes com a noção de trabalho imaterial, tal como apresentada por Lazzarato e Negri (2001) e Grisci (2006, 2008). Neles nota-se a correspondência que há dos modos de trabalhar com a mobilização de características como rapidez, responsabilidade, iniciativa e mobilidade em prol da rentabilização do trabalho.

Os modos de trabalhar no Banco Múltiplo Privado combinam com a vida líquida vivida na sociedade liquidomoderna, apontada por Bauman (2007). Ao penetrar todas as esferas da vida, as características de liquidez, de desligamento, de descartabilidade, de relacionamentos circunstanciais, de apagamento do passado, entre outras, próprias da vida líquida, tem no trabalho sua expressão irrefutável. Resulta disso, o sentimento de incerteza e insegurança que é uma constante no ambiente organizacional como se pode notar na fala a seguir.

"Mudança que afetou mesmo foi quando o banco foi comprado. Eu tive aquela fase de preocupação, sabe? ... Primeiro ficamos com muito medo de demissões e tal; é normal um empresário, quando compra uma empresa do mesmo ramo, vai querer reduzir custos, gastos enfim; estamos preocupados também em perder algo no pacote de benefícios e de incentivo ... Porque lá não tem as políticas de RH que tem aqui, pra carreira, sabe? ... é a tendência. Quando eu fiquei sabendo que o banco foi vendido, eu não acreditei, ‘me caiu os butiá do bolso', meu Deus! O que vai ser da gente agora?" (E2).

Neste banco a maioria dos entrevistados está há menos de cinco anos no banco, pois a rotatividade alta faz parte da realidade dos bancos privados. A rotatividade, entre outros aspectos dos 
modos de trabalhar e viver relatados por eles, são consequências das novas experiências espaciotemporais, devido às modificações rápidas do capitalismo flexível (Castells, 2000; Sennett, 2001), trazendo inúmeros efeitos aos modos de pensar, sentir e agir dos sujeitos, como fica evidente nos seus depoimentos. Outro ponto que chama a atenção nas falas é o vocabulário utilizado pelos entrevistados, em que privilegiam constantemente palavras como fidelizar cliente, gerenciar carteira e prospectar negócios, entre outros termos do meio bancário, largamente utilizados por gestores de negócios de bancos.

Os relatos dos entrevistados vão na direção de que quanto mais cresce a rapidez, mais decresce a liberdade (Virilio, 1996), levando-os a buscar próteses tecnológicas cada vez mais sofisticadas que, muitas vezes, invadem sua vida pessoal. São dominados pelo controle do movimento, no qual passam a viver em constante estado de emergência e permanente estado de tensão, como salienta o autor e os entrevistados demonstraram.

\begin{abstract}
"A mudança para este cargo mudou minha vida; posso trabalhar em casa, com um notebook; vou às concessionárias, vou às agências, às superintendências. Ando por tudo com o carro e celular do banco, mas também não tenho horário pra nada; se eu não botar um freio nos caras, me ligam 24 horas por dia" (E1).
\end{abstract}

As afirmações de Bauman (2007) são verificadas claramente na situação destes sujeitos, pois é preciso toda a velocidade de que se é capaz para ficar no mesmo lugar. Os bancários manifestaram insatisfação com esta situação e reclamaram da constante pressão e das condições de incerteza vividas. "Tive um crescimento constante, mas as responsabilidades aumentam juntamente com o stress" (E4). Os sujeitos foram unânimes em referir a rapidez que caracteriza o seu dia a dia de trabalho. Todos utilizaram várias vezes o termo correria ou corrido para tratar dos aspectos do seu trabalho. "Meu dia a dia é um inferno. Será que posso falar isso? (risos) Cobrança, cobrança, cobrança" (E8). Ainda sobre o ritmo de trabalho e o uso da tecnologia, os relatos dos entrevistados mostram os desdobramentos dessa velocidade em suas vidas. Conforme ressalta Enriquez (1995), as consequências disto são temíveis, mesmo que não apareçam imediatamente. Os efeitos desta exigência de velocidade vão transformando, cada dia, os modos de viver e de ser desses bancários, que passam a querer ser cada dia mais eficientes, muitas vezes passando por cima de si mesmos, de suas vontades, e até de sua condição humana, como pode ser visto na fala a seguir.

"Hoje a correria é grande, ritmo bem acelerado, acho que já me acostumei. É meio louco isso, tenho que andar com dois celulares no bolso, dirijo falando no celular, levo o notebook por tudo, até na praia consigo fazer alguma coisa, ainda mais agora com 3G" (E1).

Os comentários dos entrevistados confirmam que seus modos de ser mudaram em função do trabalho, tornando-os quase operatórios, como se nota na fala a seguir.

"Acho que aqui sempre foi acelerado assim; às vezes, eu até gosto desse ritmo, sabe; parece que me tornei bem prática e objetiva; faço tudo desse jeito, sabe? Antes de eu trabalhar no banco eu não era assim, não comia rápido, não sentia essa pressão" (E3).

Quando questionados a respeito de como se sentem em relação ao seu trabalho, os entrevistados demonstraram ressentimento e usaram termos como sob pressão, cobrança e sobrecarga. Ressalta-se que uma das agências pesquisadas pertencia a um banco múltiplo comprado pelo Banco Múltiplo Privado. Na ocasião das entrevistas fazia cerca de meio ano da incorporação acionária; estava ocorrendo naquele mês a incorporação jurídica. O clima era muito tenso entre os entrevistados. Além disso, na semana das entrevistas na agência central, uma das agências do banco adquirido havia sido fechada, sendo demitidos mais de vinte empregados e cerca de uns dez remanejados para outras agências. Destacam-se, ainda, os seguintes depoimentos.

"aqui é assim mesmo, é todo mundo meio preocupado, com umas olheiras, cheio de papéis, cheio de coisa pra fazer. Quando tu trabalha na iniciativa privada tem que toda hora se provar e tem que matar um leão por dia, senão eles vem e passam por cima, tu tem que estar ligado em tudo que está acontecendo, tem que te informar, te atualizar ..." (E2). 
"Vivia bem mais tranquila antes de trabalhar no banco; me organizava melhor. Hoje parece que vivo numa confusão, sei lá, parece uma confusão mental. Tecnologia eu sempre gostei, acho que isso é bem tranquilo, toda hora tem coisa nova aqui, mas isso eu até gosto" (E3).

Evidenciam-se nas falas dos entrevistados que eles devem atender às novas demandas do trabalho imaterial, disponibilizando no trabalho características pessoais que se tornam necessárias no desenvolvimento das novas relações de serviço, como descritas por Lazzarato e Negri (2001). Como ressalta Pelbart (2000), a condição, o conteúdo e o resultado do trabalho imaterial é a produção de subjetividade. A subjetividade é coletiva, histórica e social. Acolhe, portanto, diferentes posicionamentos relativos à experiência do trabalho. Nesse sentido, é possível constatar a existência de depoimentos que contemplam diferentes percepções, como exemplifica o relativo ao gosto pelas características em que assume o trabalho. Em geral, os relatos dos entrevistados mostram como seus modos de viver se transformaram em função do trabalho. "Eu era mais tranquila antes, aqui tem esse negócio das metas, de correr atrás, estar sempre buscando, até porque a gente é medido por isso" (E7).

O trabalho imaterial não se reproduz na forma de exploração, mas na forma de reprodução da subjetividade, como afirmam Lazzarato e Negri (2001). O trabalhador bancário há muito tempo deixou de realizar apenas atividades operacionais e burocráticas, como ratificam as falas dos entrevistados: estão sendo demandadas características próprias do trabalho imaterial, como por exemplo, a mobilização necessária para atingir o desempenho em vendas exigida. Os modos de trabalhar e de ser dizem de um sujeito capturado na lógica de obtenção e manutenção de uma condição de inclusão e sucesso, cuja origem da exigência lhes é difícil identificar. Para os bancários, seus modos de trabalhar resumem-se em fazer de tudo, atender altas metas de vendas, vislumbrarem crescimento constante, expor-se a cobranças contínuas, não ter tempo para fazer tudo, ter na tecnologia uma aliada à agilização do trabalho.

\section{Formas de lazer}

A respeito do lazer, os entrevistados relataram, majoritariamente, atividades que envolvem estar com a família e descansar. Associaram ao lazer aspectos como bem-estar, prazer, algo de que gostam e sem compromisso, o que corrobora as definições de Dumazedier (2008) e Evans e Bartolomé (1980). Como lazer, os bancários citam passear, viajar, assistir a filmes, ler, fazer compras, sair para jantar, entre outras. As atividades citadas concentram-se entre os lazeres físicos, artísticos e sociais, segundo a classificação de Dumazedier (2008).

Ressaltam-se os posicionamentos que compreendem descansar como atividade de lazer. $\mathrm{Na}$ maioria das vezes, as formas de lazer mencionadas ocorrem no final de semana, e em alguns casos, nas férias. A falta de tempo foi a reclamação principal e a maioria manifestou interesse em ter mais tempo para passar com a família, o que também haviam verificado Tanure et al. (2007).

Ao serem perguntados sobre o que gostariam de modificar em relação ao lazer, a resposta unânime foi ter mais tempo. Alguns acrescentaram ainda, ter lazer durante a semana; ter mais dinheiro; trabalhar com menos pressão; e mudar de emprego ou cargo. Nestes comentários notase o que Pelbart (2000) afirma a respeito da fronteira entre trabalho e lazer estar esfumaçando-se: tempo de trabalho e tempo de vida confundem-se.

"Gostaria de poder ter lazer e também mais tempo durante a semana, pois o trabalho é muito desgastante durante o passar do dia e à noite, quando volto para casa, fico exausta para poder desempenhar alguma atividade que seja um lazer" (E5).

No que diz respeito à família e às relações de amizade, a falta de tempo para a própria conversação, encontra-se na mesma linha dos achados de Gaulejac (2007) de que o trabalho está invadindo a vida pessoal dos sujeitos. Há uma queixa relativa à família que tem mais tempo para o lazer e não entende a falta de tempo que os assola. Além disso, os sujeitos observam que seus familiares conseguem curtir mais o lazer, não estando tão estressados quanto eles.

No entendimento a respeito do que seja lazer para os colegas de banco, todos crêem ser o 
mesmo tipo de atividade que para si. Há certo constrangimento relativo à percepção de que em realidade não conhecem as atividades de seus colegas fora do trabalho. Isto mostra como, às vezes, aspectos da vida comum são esquecidos, refletindo a sociedade liquidomoderna e as maneira como os sujeitos tendem a viver suas vidas (Bauman, 2007). "A gente não conversa muito com os colegas, que horror! Mas acho que é a mesma coisa" (E4).

As atividades de lazer são vistas como necessárias para esquecer problemas, aliviar a pressão e se divertir, concordando com o que cita Antunes (2002) a respeito da necessidade desses momentos para descansar e até mesmo para a sanidade mental dos sujeitos. "É necessário reservar um período para o lazer, a fim de esquecer os problemas e manter uma qualidade de vida, até porque eu preciso, senão enlouqueço" (E11).

Estes sujeitos costumam investir e gastar com lazer, confirmando o que Dumazedier (2008) afirma a respeito da relação existente entre formas de lazer e classe social ou profissional, além do estreito vínculo entre cultura, lazer e consumo do qual fala Sant'Anna (2001).

Quanto à tecnologia, os sujeitos mencionaram que ela facilita o lazer. Alguns, no entanto, lembraram situações em que a tecnologia pode atrapalhar o lazer, sublinhando que as tecnologias podem sequestrar o tempo da vida pessoal, afetando os limites entre o que é trabalho e o que não é.

"Primeira coisa que me veio na cabeça é que atrapalha, se não fosse e-mail e celular, não precisaria responder às coisas de casa, mas gosto de poder resolver as coisas pela internet, tipo fazer uma compra, sobra mais tempo pro lazer, né?" (E2).

Os sujeitos do Banco Múltiplo Privado não falaram em lazer compartilhado com colegas de trabalho, o que pode estar associado às questões de competição relativas ao atingimento das metas crescentes. Também não citaram atividades de lazer que abrangem, segundo a classificação de Dumazedier (2008), os lazeres práticos. Para o autor a escolha do tipo de lazer está ligada à classe socioprofissional dos sujeitos e às suas necessidades de realização. Possivelmente, com as demandas do trabalho imaterial bancário, estas necessidades de realização dos sujeitos vão ser modificadas, podendo refletir-se nas escolhas relacionadas ao lazer. Por exemplo, com a exigência cada vez maior de um trabalho intelectual, supõe-se que surja a necessidade de realização de um lazer mais manual. Quanto às possibilidades relativas a lazer, os sujeitos referem algo necessário para esquecer problemas, a falta de tempo para o lazer e para a família, algo prazeroso relativo ao bem-estar, o descanso, viajar, passear, ler, assistir a filmes, a limitação aos fins de semana, os gastos, a tecnologia que, ao mesmo tempo, facilita e atrapalha.

\section{Interação dos modos de trabalhar com o lazer}

Os bancários referem não conseguir desligar-se do trabalho, ao sair do banco. O trabalho e as preocupações relativas a ele acompanham os sujeitos em seu tempo livre, uma vez que, como destaca Dejours (2008), o funcionamento psíquico não é divisível. As falas dos bancários são exemplares em relação a essa afirmação.

"Sonho com os clientes, com o telefone. Se ouço o barulho do toque do celular, dá um pânico, às vezes meus amigos ligam enganados para o celular do banco, dá um alívio quando percebo que é eles; outras vezes não é, aí é rolo certo" (E1).

"Às vezes parece que estou trabalhando o tempo inteiro, mesmo sem levar trabalho pra casa. A cabeça é uma só, eu tenho um estresse muito grande, às vezes tenho insônia, estou sempre cansado, às vezes não tenho ânimo nem pra comer" (E2).

A fluidez das fronteiras entre tempo de trabalho e de não trabalho, característica do trabalho imaterial bancário, corrobora as afirmações de Pelbart (2000) no sentido de que o trabalho afeta a vida como nunca. Conforme já exposto, os familiares e amigos percebem e reclamam da ausência e da pressão vivida por estes bancários. Não bastasse a tensão no trabalho, estes sujeitos, na sua vida pessoal, também convivem com cobranças, já que não possuem muito tempo para se dedicar à família, 
aos amigos, exercícios físicos, entre outras atividades a serem realizadas em horas de lazer. Embora haja a tentativa de negociar com a gerência ou resistir de alguma maneira, na maioria das vezes se percebem impotentes para mudar tal condição. E desta negociação que se confirma frustrada, pois acabam cedendo, resultam sentimentos de irritação, indignação e incomodação.

"Minha esposa percebe que eu chego sempre meio estressado em casa, meio fora do ar, no trabalho dela também é assim. Hoje eu não consigo me organizar e participar mais das coisas da minha família, meus amigos reclamam que estou ausente" (E2).

"Todos possuem empregos menos estressantes. Quero ver, quando eu ganhar meu filho como vai ser; é depois da gravidez comecei a pensar um pouco diferente, pesar outras coisas" (E8). Para os bancários do Banco Múltiplo Privado, o trabalho já impediu ou impede o lazer, seja em razão das horas extras, das reuniões fora do horário de trabalho, dos trabalhos no final de semana, ou, indiretamente, em razão da experimentação de cansaço, de preocupações e falta de tranquilidade mesmo nas férias.

Demonstraram estar sempre balançando entre submeter-se, se conformar, ceder; ou, resistir, se irritar, se indignar, confirmando o que dizem Guattari e Rolnik (1996) sobre como os sujeitos vivem a subjetividade. Os depoimentos dos sujeitos foram em tom de desabafo.

“Às vezes, minha família viaja a lazer e eu tenho que ficar em casa trabalhando, pois os dias não são flexíveis no banco. Minha família consegue direcionar mais o tempo que deseja tirar férias ... Isso acaba engessando minhas possibilidades de férias, para ficar com minha família e amigos. Sinto-me de mãos atadas, quando isso acontece; mas não posso e não consigo mudar tal situação" (E5).

"mas me impede de fazer atividade física, agora a gente até tem laboral, já é alguma coisa; mas talvez o banco pudesse fazer algo por nós, sei lá. Quando acontece de não poder buscar meu filho, por exemplo, me sinto muito mal; é que às vezes as pessoas não pensam nos colegas" (E7).

E ainda: "quando engravidei, não consegui curtir a gravidez, fiquei mais estressada que o normal e não recebi apoio" (E8). Como destaca Enriquez (1995), todos vivem na ânsia de não estar à altura, precisando ser ao mesmo tempo conformados, adaptáveis e inovadores, o que denota uma contradição em si. Mesmo diante de uma situação programada com antecedência, se houver uma solicitação de última hora, por parte do trabalho, a decisão a ser tomada privilegia o trabalho. Embora afirmem um desejo de negociação, já introjetaram um modo de ser que expressa compromisso em primeiro lugar, primeiro o trabalho depois o lazer, sem trabalho não se tem lazer. Invariavelmente, expressaram um sentimento de mal-estar em relação a isso, e invariavelmente cedem a favor do trabalho. "Isso já se tornou meio normal, quando chego cedo a casa é até estranho" (E2).

"mais de uma vez, tive que ir viajar no sábado ao invés de sexta, marcaram reunião ou tinha outra coisa, agora parece que já me acostumei, não programo mais nada, eu tento negociar de alguma forma, mas sempre rola uma espécie de manipulação, sabe? A gente acaba cedendo" (E3).

Há a constatação de que esta situação sempre foi assim, numa ideia de naturalização. No entanto, apenas três dos sujeitos do Banco Múltiplo Privado estão há mais de dez anos no banco, tendo acompanhado as maiores mudanças de posicionamento de mercado, passando até mesmo por uma privatização. Sennett (2001) alerta que as consequências do capitalismo flexível geram ansiedade e riscos, sendo, muitas vezes, incompreensíveis, conforme denotam as falas dos bancários. "Talvez em outro emprego seja diferente; mas em geral nos bancos privados acho que é assim mesmo" (E3).

Os resultados do presente estudo corroboram as reflexões de Gaulejac (2007) a respeito da sociedade supermoderna, em que é preciso adaptar-se à dura realidade e, ao mesmo tempo, passar por cima dos estados da alma. Estes sujeitos são produtores e produtos do sistema, conforme será visto no item a seguir. Os relatos evidenciam que há interferência dos modos de trabalhar no tocante ao lazer. Tal interferência normalmente é negativa, pois os sujeitos, além de trabalhar mais horas, quando em casa, encontrar-se-iam cansados. Em relação à interação dos modos de trabalhar com o lazer, destacam os sujeitos que nunca se desligam totalmente do trabalho, o trabalho já lhes impediu ou impede o lazer; os familiares não entendem e reclamam; querem ter mais tempo para o lazer e a família, tentam 
negociar horas extras e reuniões mas invariavelmente acabam cedendo, nunca estão totalmente tranquilos; mesmo em férias, o cansaço impede o lazer.

\section{Trabalho imaterial, lazer e a vivência de dilemas pessoais contemporâneos}

Dos relatos dos sujeitos se depreendem os dilemas por eles vividos no trabalho imaterial bancário, conforme se verá a seguir. Abrir mão de algo por causa do trabalho, mesmo que comprometa seu relacionamento familiar, ou sua própria saúde, é prática aceita entre eles.

O medo de ficar sem emprego é o elemento definidor na priorização do trabalho em detrimento do lazer - obrigações em primeiro lugar. Como lembram Gaulejac (2007) e Bauman (2007), a ameaça de perder o posto ou de ser visto como obsoleto desafia a todos, independentemente de qual seja sua inserção no mundo do trabalho. Outro elemento definidor para a escolha do trabalho é a questão da remuneração - dinheiro para pagar as contas. Alguns comentários exemplificam isto: "Ficar sem emprego, remuneração, eu tenho medo de ficar sem emprego, mas também não tenho tempo de procurar algo melhor" (E2); "As pessoas precisam do trabalho para sobreviver, o lazer fica em segundo plano" (E8).

Os sujeitos compartilham a percepção de que para o banco são considerados apenas recursos, cujo rendimento deve ser satisfatório.

Além da remuneração e do futuro, os sujeitos mencionaram preocupações com aspectos da vida familiar. Outros se mostraram contrariados, pois pensam no dinheiro, mas não têm certeza de que esta é a alternativa correta. Ao priorizarem o trabalho para proporcionar condições favoráveis a si e à família, falta-lhes tempo e a família reclama ausência; ao priorizarem o tempo livre para si e para a família, correm o risco de não permanecerem no emprego.

Alguns dos sujeitos do Banco Múltiplo Privado disseram duvidar de que possuam lazer como alternativa. Segundo eles, diante da pressão e cobrança, a escolha é entre trabalho e saúde, já que, se optassem pelo lazer, estariam fora do sistema.

"Entre trabalho e lazer? Nem sei se a gente tem esta opção, eu diria entre trabalho e saúde, lazer ficar lá pro fim. Ainda assim, entre trabalho e saúde, a gente fica com o trabalho; eu sei de gente aqui que está um tempão pra fazer uns exames e vai desmarcando, desmarcando, desmarcando" (E4).

Desta forma, os riscos à saúde relacionados ao trabalho podem ser potenciados, como, por exemplo, crises de estresse, depressão e doenças coronarianas. Também o aumento das tarefas e das responsabilidades e o alto ritmo imposto incrementam a sensação de estar sempre em débito, como já disseram Huy e Mintzberg (2003).

Entre os bancários do Banco Múltiplo Privado, verificou-se a tendência a considerar que todos, os mais novos e os mais antigos, estão no mesmo barco. É possível que tal consideração se sustente, porque todos querem sobreviver no atual mundo do trabalho, estando condenados a vencer e a apresentar resultados de produtividade recordes cada dia. No entanto, três dos entrevistados assinalaram um aspecto singular a respeito da submissão ao trabalho. O uso que fizeram da expressão estão de passagem, ao referirem-se aos empregados mais novos, ratifica o que Sant'Anna (2001) esclarece a respeito da necessidade de leveza dos corpos, hoje em dia, que evitam carregar muita memória e permanecer por muito tempo num mesmo lugar. Relataram: "os mais antigos aturam mais, se submetem mais. Os mais novos parecem estar de passagem" (E9).

\footnotetext{
"Parece que os mais novos não se oprimem tanto, não se deixam dominar, querem sugar tudo de bom que o banco oferece, estão de passagem, já os mais antigos tem mais medo, aceitam mais, morrem de medo de ficar sem emprego" (E4).

"Eu percebo que os jovens não se submetem às pressões como os mais velhos, eles não aceitam essas pressões dos banqueiros, com raras exceções. É claro, estão de passagem, os mais antigos é que sofrem mais com a falta de oportunidade" (E8).
} 
A ocupação de cargos de chefia não se mostrou um elemento diferenciador da vivência dos dilemas pessoais contemporâneos, relativos à relação trabalho e lazer, uma vez que os sujeitos foram produzidos dentro da lógica da mobilização e rentabilização de si em prol do trabalho: "com certeza, quando se pega um cargo, já se sabe que não dá pra dizer não" (E1); ou "todos sofrem pressão aqui" (E10).

As falas dos sujeitos vão em direção aos achados de Lopez-Ruiz (2007), a respeito do conjunto de valores e normas de as grandes corporações orientarem a conduta dos sujeitos que nelas trabalham. Salienta-se que onze dos quinze entrevistados têm cargo gerencial e que nas agências cerca de setenta a oitenta por cento dos empregados têm cargo gerencial, o que faz parte da política do banco. Os entrevistados pareciam até gostar disso, mas o Sindicato denunciou, em conversa informal, que isto estimula a competitividade e justifica ou neutraliza algumas ações agressivas dos bancos. É como se estes empregados passassem a ter um contrato diferenciado, com regras severas que ficam encobertas pelo brilho e status do cargo. O cargo os aprisiona emocionalmente, e basta um deslize para que sejam substituídos, ressaltou o representante do Sindicato. O relato a seguir exemplifica isto: "ambos trabalham bastante, até porque isso é bem incentivado aqui, por causa das oportunidades de carreira. Quem está no cargo tem de se manter, e quem não está, está buscando um cargo" (E2).

Como disseram: "passam a impressão de que temos que passar por isso para chegar lá" (E3). No trabalho imaterial bancário, a vivência de dilemas relativos à interação trabalho e lazer, guarda algumas particularidades em relação à aceitação ou desprezo que sofrem os sujeitos. Cabe lembrar que, ao se posicionarem a respeito do que é lazer, os bancários disseram ser algo prazeroso a proporcionar bem-estar e, ainda, que as atividades de lazer são necessárias para esquecer os problemas do dia a dia. Entretanto sua visão sobre alguém que opta pelo lazer contém adjetivos como folgado, desinteressado, vagabundo, desleixado e louco. Além disso, quem opta pelo lazer estaria revelando falta de coleguismo, incapacidade de pegar junto, ou que pensa somente no seu bem-estar e na sua saúde. Já quem opta pelo trabalho é visto como bajulador, fominha, corinho, ou realista. Diante disso, nota-se que na vivência de um dilema o sujeito se encontra só, o que exacerba o sofrimento. Própria do dilema, a situação de não haver saída favorável torna-se uma constante, já que o sujeito não encontra acolhida junto a seus pares, como se pode verificar na Tabela 2, que evidencia a armadilha que prende o sujeito, independentemente da escolha que venha a fazer.

Tabela 2

\section{Respostas ao Dilema Trabalho e Lazer}

\begin{tabular}{lll}
\hline Entrevistado & $\begin{array}{l}\text { Como alguém que, entre o trabalho e o lazer, opta } \\
\text { pelo trabalho é visto pelos colegas? }\end{array}$ & $\begin{array}{l}\text { Como alguém que, entre o trabalho e o lazer, opta } \\
\text { pelo lazer é visto pelos colegas? }\end{array}$ \\
\hline E4 & $\begin{array}{l}\text { Que pergunta interessante. Puxa-saco, aconteceu } \\
\text { comigo essa semana, tínhamos uma reunião, aquelas } \\
\text { pra ajoelhar no milho e levar uma mijada, e atrasou }\end{array}$ & $\begin{array}{l}\text { Vagabundo, desinteressado, não pega junto, essas } \\
\text { coisas. }\end{array}$ \\
& $\begin{array}{l}\text { umas 4 horas. É uma palhaçada o que eles fazem com } \\
\text { a gente, teve gente que voltou pra trabalhar, eu e mais } \\
\text { um grupo ficamos lá esperando, trocando ideias e }\end{array}$ \\
& $\begin{array}{l}\text { contando piadas. Foi o que eu mais aproveitei da } \\
\text { reunião, quem voltou parecia que era idiota, foi mal } \\
\\
\text { visto, quem ficou era legal, parceria, ainda bem que } \\
\end{array}$ &
\end{tabular}

\section{Puxa-saco, corinho, quer ser promovido, quando} precisa ficar, tudo bem, mas nem sempre precisa.

E8

Como puxa saco, fominha, sei lá, não é bem visto.

Puxa saco ou Caxias.
Acho que depende do gestor, aqui se ficar mais de 8 horas não é muito bem visto, mas se não ficar é vagabundo, desinteressado.

Vagabundo, louco, (risos), essas coisas.

$\mathrm{O}$ folgado (risos). 


\section{Tabela 2 (continuação)}

\begin{tabular}{|c|c|c|}
\hline Entrevistado & $\begin{array}{l}\text { Como alguém que, entre o trabalho e o lazer, opta } \\
\text { pelo trabalho é visto pelos colegas? }\end{array}$ & $\begin{array}{l}\text { Como alguém que, entre o trabalho e o lazer, opta } \\
\text { pelo lazer é visto pelos colegas? }\end{array}$ \\
\hline E10 & $\begin{array}{l}\text { Acho que se isso ocorre com muita frequência é mal } \\
\text { visto pelos colegas. }\end{array}$ & Normalmente. \\
\hline E11 & Alienado. & Vagabundo! (risos) \\
\hline E12 & $\begin{array}{l}\text { Muito egoísta, com os seus próprios familiares e } \\
\text { consigo mesmo. }\end{array}$ & $\begin{array}{l}\text { Muito nem aí pra nada, ou que opta sempre pela } \\
\text { família. }\end{array}$ \\
\hline E13 & Puxa-saco. Ou uma pessoa que pensa na realidade? & $\begin{array}{l}\text { Desleixado ou alguém que pensa no seu bem estar e } \\
\text { na sua saúde. }\end{array}$ \\
\hline
\end{tabular}

Marcellino (2006) lembra os preconceitos associados ao lazer e destaca que o descanso e o divertimento são os valores mais associados ao lazer, o que também foi afirmado pelos bancários. Além disso, o autor afirma que, nos momentos de lazer, há a possibilidade de tomada de contato, de percepção e de reflexão sobre as pessoas e as realidades nas quais se inserem. Esta oportunidade de refletir sobre a condição em que vivem os sujeitos do Banco Múltiplo Privado realmente parece fazerlhes falta.

Na modernidade líquida, tudo passa a ser responsabilidade do sujeito, intensificando ainda mais os seus medos (Bauman, 2007). Os bancários do Banco Múltiplo Privado se moldam às novas situações de trabalho que surgem, alterando seus modos de viver e de ser, sua vida pessoal e o lazer, praticamente sem questionar. Há que considerar, ainda, que "forças poderosas e estratégias insuspeitadas redesenham, a cada dia que passa nosso rosto incerto no espelho do mundo" (Pelbart, 2000, p. 11). Novos modos de viver, de ser e de trabalhar desses bancários estão sendo construídos e transformados diariamente.

O trabalho imaterial no Banco Múltiplo Privado exige características pessoais que facilitam as tarefas, como passar confiança aos clientes, e habilidade de planejar o tempo, dada a velocidade exigida e as metas sempre crescentes. A aceleração contida no dia a dia desses sujeitos por vezes os impede de darem-se conta das exigências que sofrem e dos dilemas vividos. Além disso, o trabalho imaterial bancário se mostrou potenciado pelo controle sempre presente, na forma de indicadores gerenciais, que possibilitam verificar todos os dias se as metas foram atingidas, apontando quais os empregados que não as cumpriram.

A interação do trabalho imaterial com o lazer constitui o dilema pessoal contemporâneo. Os sujeitos vivem dilemas pessoais, dadas as condições de vida e trabalho atualmente, conforme apresentam Sennett (2001), Bauman (2007) e Gaulejac (2007). Os relatos dos sujeitos indicam que os modos de trabalhar podem potenciar a vivência de dilemas e favorecer o sofrimento dos sujeitos (Dejours, 2008).

\section{Considerações Finais}

Neste estudo foi possível verificar que os modos de trabalhar bancário têm características do trabalho imaterial e interferem no lazer dos bancários, bem como em sua vida pessoal, podendo disto resultar dilemas pessoais contemporâneos, uma vez que, em situação de escolha entre o dever e o lazer, não há como evitarem o não satisfatório, o sujeito, a família, os amigos ou o trabalho. Há, ainda, a imagem negativa perante os demais, já que, ao escolher o trabalho, o sujeito é tido como muito egoísta com seus próprios familiares e consigo mesmo; ao escolher o lazer é tido como muito nem aí pra nada, ou aquele que opta sempre pela família. Não há, então, boa escolha (Bauman, 2007), o que caracteriza o dilema. 
Os resultados da pesquisa apontam que os sujeitos convivem constantemente com a necessidade de optar entre o trabalho e o lazer. Neste dilema pessoal, a responsabilidade pela escolha sempre recai sobre os sujeitos; o cenário do trabalho emite mensagens enfáticas dos possíveis prejuízos pela negligência para com o dever. Talvez seja possível vir até mesmo a pensar na existência de falsos dilemas, devido às exigências e controle da organização do trabalho para com os sujeitos, tanto que no Banco Múltiplo Privado, onde os modos de trabalhar atrapalham ou impedem o lazer; todos os sujeitos mencionaram a frase "trabalho em primeiro lugar".

Para os bancários, lazer é essencial na vida e necessário para esquecer problemas cotidianos, proporciona prazer, bem-estar e descanso. Porém, se evidenciou que abrir mão do lazer é prática frequente. Quando o dilema entre trabalho e lazer se instala, quase sempre a escolha recai no trabalho, pois os sujeitos são pressionados para tal; o contexto que os cerca indica que devem fazê-lo. Tomados pelo medo, pela insegurança e ansiedade, e sem boa alternativa, racionalizam como modo de enfrentamento: sem trabalho não se tem lazer. Ocorre, entretanto, que os dilemas não são compreendidos pelos sujeitos como tais nitidamente. Embora possam, em alguns momentos, aparecer de modo mais visível, em geral encontram-se num contexto de trabalho produtor de estilos de vida condizentes com as necessidades do trabalho.

Tal qual a literatura indica, os dados levantados no Banco Múltiplo Privado demonstram que a máxima sempre acima das expectativas é a que permeia e é valorizada hoje em dia (Gaulejac, 2007; Bauman, 2007). As novas tecnologias e a nova estrutura do trabalho bancário convidam os sujeitos a se reinventarem, criando diariamente novas formas de ser e agir, novos modos de viver no contexto do trabalho. Bauman (2007) lembra que o ambiente imprevisível e de fluxo rápido, presente na vida líquida, colabora para aumentar os dilemas dos sujeitos.

Para os sujeitos, lidar com os dilemas pessoais contemporâneos é tarefa nada fácil, principalmente quando os modos de trabalhar não colaboram para que sejam amenizados, sendo, pelo contrário, ainda mais intensificados, como no caso do Banco Múltiplo Privado. Nas entrevistas, alguns sujeitos demonstraram não poder refletir criticamente na sua condição no banco, provavelmente porque os modos de gestão dos bancos utilizem estratégias que provoquem o anestesiamento de algumas questões, seja por coerção ou por sedução. $O$ trabalho destes sujeitos é estressante, pois têm um ritmo acelerado e constante cobrança por metas de vendas. A pressão os acompanha ao ambiente doméstico, na forma de cansaço ou de mal-estar.

Dos relatos advindos do Sindicato dos Bancários de Porto Alegre e da situação vivida pelos sujeitos do Banco Múltiplo Privado, a pressão é a realidade vivida nos bancos atualmente, não apenas dos bancos privados, mas também nos bancos públicos com carteira comercial. O sindicato alertou ainda que o Banco Múltiplo Privado seria aquele com as piores políticas em prol de seus empregados, excesso de pressão no ambiente de trabalho, cobranças abusivas por metas e prática de demissões, entre outras. No que tange ao foco desta pesquisa, a partir da análise dos dados coletados, esta informação realmente parece que se confirmou.

Para futuros estudos em bancos de caráter comercial, principalmente nos privados, alerta-se que justamente devido à correria vivida pelos bancários, as pesquisas são difíceis de serem realizadas, demandando maior empenho do pesquisador. Para exemplificar, registra-se que, diante das solicitações para a coleta de dados no Banco Múltiplo Privado, surgiram comentários do tipo: "Tem que ser aquelas de marcar!"; ou, "Nossa, é enorme isso aqui!". Esta é a realidade vivida por sujeitos que se vêem sem tempo a perder.

Uma contribuição desta pesquisa refere-se ao fato de ser um estudo qualitativo. Segundo Scanfone, Carvalho e Tanure (2007), há necessidade de compreender estas questões quantitativa e também qualitativamente. A presente pesquisa explicitou outras questões e conflitos gerados pela predominância do trabalho sobre o tempo livre dos sujeitos, avançando assim em análise mais detalhada. Para a gestão dos bancos, esta pesquisa pode contribuir como alerta para as consequiências que envolvem os modos de trabalhar extenuantes. 
Para pesquisas futuras, assinalam-se algumas possibilidades. A exploração de possível conotação ética e religiosa nos relatos dos sujeitos que indicaram o trabalho em primeiro lugar, ou trabalho à frente da saúde, as propagandas dos bancos que, de certa forma, refletem a ausência de lazer dos bancários, enaltecem, por exemplo, que o banco é 24 horas ou que o gerente atende até a meia-noite; a ausência de atividades de lazer do tipo práticas, que envolvem trabalhos manuais, culinária e jardinagem realizadas, em geral, em casa.

Para pesquisas futuras, sugere-se ainda considerar a pertinência da apresentação opção pelo lazer ou pelo trabalho, dada a complexidade que envolveu a temática, que não pode ser aprisionada em ideia de dicotomias, bem como a ampliação em termos de outras categorias profissionais.

\section{Artigo recebido em 19.07.2010. Aprovado em 06.06.2011.}

\section{Referências}

Antunes, R. (2002). Os sentidos do trabalho: ensaio sobre a afirmação e a negação do trabalho. São Paulo: Boitempo.

Bacha, M. L. de, Vianna, N. W. H., Souza, S. S., \& Perez, G. (2008). Lazer nas classes populares: uma proposta de segmentação. Organização \& Sociedade, 15(44), 81-99.

Banco Central do Brasil. (2009). Sistema financeiro nacional: composição e evolução do SFN. Recuperado em 26 julho, 2009, de http://www.bcb.gov.br/?SFNCOMP

Bardin, L. (2004). Análise de conteúdo. Lisboa: Edições 70.

Bauman, Z. (2007). Vida líquida. Rio de Janeiro: Zahar.

Bessi, V. G., \& Grisci, C. L. I. (2006, setembro). Trabalho imaterial e resistência no cotidiano do trabalho. Anais do Encontro Nacional da Associação Nacional de Pós-Graduação e Pesquisa em Administração, Salvador, BA, Brasil, 30.

Brett, J. M., \& Stroh, L. K. (2003). Working 61 pus hours a week: why do managers do it? Journal of Applied Psychology, 88(1), 67-78. doi: 10.1037/0021-9010.88.1.67

Castells, M. (2000). A sociedade em rede. São Paulo: Paz e Terra.

Dejours, C. (2008). Para uma clínica da mediação entre psicanálise e política: a psicodinâmica do trabalho. In S. Lancman \& L. I. Sznelwar (Orgs.), Christophe Dejours: da psicopatologia à psicodinâmica do trabalho (pp. 187-216). Rio de Janeiro: Editora Fiocruz, Brasília: Paralelo 15.

De Vries, M. F. R. K. (2004). Putting leaders on the couch. Harvard Business Review, 71(1), 65-71.

Dumazedier, J. (2008). Sociologia empírica do lazer. São Paulo: Perspectiva SESC.

Edwards, J. R., \& Rothbard, N. P. (2000). Mechanisms linking work and family: clarifying the relationship between work and family constructs. Academy of Management Review, 25(1), 178199.

Enriquez, E. (1995). Prefácio. In E. Davel \& J. Vasconcelos (Orgs.), "Recursos" humanos e subjetividade (pp. 7-22). Rio de Janeiro: Vozes.

Evans, P., \& Bartolomé, F. (1980). Must success cost so much? London: Grant McIntyre. 
França, L. H. F. P. (2009). Influências sociais nas atitudes dos 'top' executivos em face da aposentadoria: um estudo transcultural. Revista de Administração Contemporânea, 13(1), 17 35. doi: 10.1590/S1415-65552009000100003

Freitas, M. E. (1998). Contexto social: o mundo do trabalho, a família e os "eternos" adolescentes. RAE Light, 5(2), 2-6.

Gaulejac, V. de (2007). Gestão como doença social: ideologia, poder gerencialista e fragmentação social. São Paulo: Idéias \& Letras.

Gil, A. C. (2007). Métodos e técnicas de pesquisa social. São Paulo: Atlas.

Gorz, A. (2005). O imaterial: conhecimento, valor e capital. São Paulo: Annablume.

Grisci, C. L. I. (2006). Trabalho imaterial. In A. D. Cattani \& L. Holzman (Orgs.), Dicionário de trabalho e tecnologia (pp. 327-329). Porto Alegre: Ed. UFRGS.

Grisci, C. L. I. (2008). Trabalho imaterial, controle rizomático e subjetividade no novo paradigma tecnológico. RAE-Eletrônica, 7(1), 67-89. doi: 10.1590/S1676-56482008000100005

Guattari, F., \& Rolnik, S. (1996). Micropolítica: cartografias do desejo (4a ed.). Petrópolis: Vozes.

Huy, Q. N., \& Mintzberg, H. (2003). The rhythm of change. MIT Sloan Management Review, 44(4), 79-84.

Lazzarato, M., \& Negri, A. (2001). Trabalho imaterial: formas de vida e produção de subjetividade. Rio de Janeiro: DP\&A.

Lopez-Ruiz, O. J. (2007). Executivos das transnacionais e o espírito do capitalismo: capital humano e o empreendedorismo como valores sociais. Rio de Janeiro: Azougue Editorial.

Mansano, S. R. V. (2009). Transformações da subjetividade no exercício do trabalho imaterial. Estudos e pesquisa em psicologia, 9(2), 512-524.

Marcellino, N. C. (2006). Estudos do lazer: uma introdução (4a ed.). Campinas: Autores Associados.

Pelbart, P. P. (2000). A vertigem por um fio: políticas de subjetividade contemporânea. São Paulo: Iluminuras.

Perista, H., Maximiano, S., \& Freitas, F. (2000, abril). Família, gênero e trajetórias de vida: uma questão de (usos do) tempo. Anais do Congresso Português de Sociologia, Coimbra, Portugal, 4. Recuperado em 16 maio, $2010, \quad$ de http://www.aps.pt/cms/docs_prv/docs/DPR462dffeb8da19_1.PDF

Roesch, S. M. A. (2005). Projetos de estágio e de pesquisa em administração. São Paulo: Atlas.

Sant'Anna, D. B. de (2001). Corpos de passagem: ensaios sobre a subjetividade contemporânea. São Paulo: Estação Liberdade.

Scanfone, L., Carvalho, A., Neto, \& Tanure, B. (2007, setembro). Tempos de trabalho e de nãotrabalho: o difícil equilíbrio do alto executivo entre a carreira, as relações afetivas e o lazer. Anais do Encontro Nacional da Associação Nacional de Pós-Graduação e Pesquisa em Administração, Rio de Janeiro, RJ, Brasil, 31.

Sennett, R. (2001). A corrosão do caráter: conseqüencias pessoais do trabalho no novo capitalismo. Rio de Janeiro: Record. 
Tanure, B., Carvalho, A., Neto, \& Andrade, J. (2007). Executivos: sucesso e (in)felicidade. Rio de Janeiro: Elsevier.

Tonelli, M. J., \& Alcadipani, R. (2003, setembro). O trabalho dos executivos: a mudança que não ocorreu. Anais do Encontro Nacional da Associação Nacional de Pós-Graduação e Pesquisa em Administração, Atibaia, SP, Brasil, 37.

Virilio, P. (1996). Velocidade e política. São Paulo: Estação Liberdade. 